\title{
Specialised alcohol treatment services are a luxury the NHS cannot afford
}

\author{
Jason Luty/Thomas Carnwath
}

\section{Summary}

Is alcoholism an illness or merely a self-inflicted indulgence? Can we afford specialist alcohol treatment services? Do they even work? Should the tax payer foot the bill? Is the lack of such services 'perverse'?

In this lively debate Drs Carnwath and Luty weigh up the pros and cons of controlling the effects of 'our favourite drug'.

\section{Declaration of interest}

J.L.: none / T.C.: none.

\section{For}

The National Health Service (NHS) is now firmly in financial crisis and redundancies of up to 20000 staff are a real possibility. ${ }^{1}$ As Frank Dobson, the former health minister, stated, 'There is no place in the modern NHS for . . . hanging onto outdated, ineffective, treatments. ${ }^{2}$ The NHS currently spends $£ 75-250$ million annually on specialised alcohol treatment services, whose object is to reduce the excessive consumption of alcohol. ${ }^{3,4}$ There are around 300 advice and counselling services, 100 day programmes and nearly 200 residential programmes. ${ }^{5}$ Obviously, vastly more is spent by other parts of the NHS dealing with the numerous complications of alcohol misuse.

Around 1 in 13 men in Britain ${ }^{6}$ are dependent on alcohol. Some would regard these people as 'ill'; many others would not, presumably considering alcoholism as self-inflicted. ${ }^{7}$ This argument is largely popular among academics and probably would be of little interest if treatment were effective. Unfortunately the success of current specialist alcohol treatment is not proven. ${ }^{8}$ Motivational interviewing has been the flagship of psychological treatment of substance use problems for some time. This involves the client, rather than the therapist, giving the reasons for abstinence and providing a list of problems caused by their alcoholism. This seems modestly effective in opportunistic samples - that is people who did not realise they were drinking too much. ${ }^{9}$ Moyer et al's meta-analysis found no evidence for significant benefits in people from treatment-seeking populations (the people likely to attend specialised alcohol services). Neither of the two largest randomised studies of psychological treatment for alcohol problems have shown any significant difference between the treatment modalities under review (these included motivational interviewing, community reinforcement, cognitivebehavioural therapy and twelve-step approaches). ${ }^{10,11}$ The UK Alcohol Treatment Trial outcomes showed that, on average, participants were still consuming 137 units per week after 1 year around five times the recommended drinking limits, or the equivalent of 68 pints of beer per week. No objective improvements in biochemical markers (such as $\gamma$-glutamyl transferase) were observed, although the investigators dismissed these outcomes in preference to self-reported data.

The results of pharmacological treatment of alcohol misuse have been equally disappointing. Despite great optimism, outcomes for disulfiram treatment are poor ${ }^{12}$ and the two largest trials of acamprosate and naltrexone showed no significant benefits. ${ }^{13,14}$ Some impressive results have been reported but these trials have had unrealistic medication adherence rates (often exceeding 80\%) and are often funded by the drug manufacturers. ${ }^{15}$ Lloyd and colleagues ${ }^{16}$ found that fewer than $3 \%$ of people misusing alcohol have been treated for alcohol problems. By contrast, Vaillant estimates that $2-3 \%$ of people with alcoholism abstain spontaneously each year in the community. ${ }^{17}$ Hence, demonstrating the effectiveness of pharmacological treatment in small, highly selective or unrandomised trials could easily be explained by patient selection bias.

Thirty years ago Edwards and colleagues ${ }^{18}$ reported no significant difference in their 1-year trial involving a group of people with alcohol problems who were randomised to receive a single advice session or extensive, multidisciplinary support. To date, there has been no evidence published that significantly changes this finding. I would like to quote Professor Simon Wessely's comments on psychological debriefing, 'It is inevitable that when a cherished belief is challenged, various counterclaims are made the evidence is for the wrong type of [treatment], the trials were not well done, elements of [treatment] could still "work", the testimonies of those who are certain it helped them cannot be discounted ... There can be no doubt that those who are attempting to help people . . . have noble motives, but that sadly is not enough. ${ }^{19}$ For specialised alcohol treatment services the buck stops here!

Jason Luty

\section{Against}

This country cannot afford not to have a specialist alcohol service. Here are some alarming facts, recently highlighted by the Prime Minister's Strategy Unit: ${ }^{3}$

(a) each year there are about 22000 premature deaths due to alcohol misuse, including about 1000 suicides;

(b) seventy per cent of all admissions to accident and emergency units at peak times are alcohol-related;

(c) alcohol misuse results in 17 million working days lost per year;

(d) more than 1 million children are at risk because of parental alcohol misuse, which also accounts for a third of domestic violence;

(e) it is estimated that alcohol misuse costs the NHS $\mathfrak{E} 1.4-1.7$ billion a year;

(f) alcohol-related crime and disorder costs the country annually $£ 7.3$ billion and lost productivity $£ 6.4$ billion. 
The majority of dual-diagnosis problems are caused by alcohol. ${ }^{20}$ If any illicit drug, or indeed any disease, caused this scale of damage, it is unthinkable that huge efforts would not be made to mitigate the problem. But because alcohol is, in the words of the former Prime Minister Tony Blair, 'our favourite drug' ${ }^{3}$ a cloak of denial has descended over the eyes of our policy-makers, and to some extent also the general public. In most of the country almost nothing is being done to reduce the problem or to treat its consequences.

Alcohol treatment services have for the most part disappeared, their resources transferred to general medicine or psychiatry, or to the treatment of illicit drug dependence. A recent national survey showed that in some parts of the country less than one in a hundred dependent alcohol misusers had access to appropriate treatment. ${ }^{21}$ It is not as if alcohol treatment does not work - Dr Luty has been somewhat selective in his use of evidence. Systematic reviews have indicated that alcohol treatment is indeed effective. These include the large Mesa Grande survey of 381 controlled trials, ${ }^{22}$ and also studies commissioned by governments in Sweden, ${ }^{23}$ Scotland, ${ }^{24}$ Australia ${ }^{25}$ and England. ${ }^{26}$ These studies also show that various psychological approaches produce good outcomes, and also that medications such as acamprosate, naltrexone and disulfiram play an important supporting role, albeit in particular circumstances. There are also many promising new medications in the pipeline. ${ }^{9}$ It is true that the largest alcohol research study ever undertaken (Project MATCH in the USA, 1997), showed that three different types of psychological treatment (twelve-step facilitation, cognitive-behavioural coping skills and motivational enhancement therapy) were all equally effective, ${ }^{28}$ but this is scarcely a justification for abandoning all of them. A recent UK study showed that each pound spent on treatment saved $\mathfrak{£} 5$ in terms of other health and social costs. ${ }^{29}$

Curiously, there are many national targets, which if approached rationally would include alcohol treatment as a core component. These include health targets such as reducing cancer, heart disease and health inequalities, and social targets such as reducing crime and promoting safe neighbourhoods. It is partly because there are few alcohol specialists locally that this intervention is too often ignored in local plans to meet these targets. There are strong voices shouting for more liver transplants, but none or few for preventing their need by providing basic alcohol services. By the same token medical students receive only $6 \mathrm{~h}$ of tuition concerning alcohol misuse and related problems in the whole of their 6 years of training. ${ }^{30}$

If commissioners have been interested at all in alcohol, it is by the idea of 'brief interventions', presumably because they are cheap. If general practitioners identify and counsel people with alcohol problems, there is good evidence that a proportion will modify their ways, enough to make a sizeable difference in terms of population health at a small cost. ${ }^{31}$ But brief interventions work most effectively where they are part of a comprehensive treatment system. In 2006 the Department of Health commissioned Models of Care for Alcohol Misuse, ${ }^{32}$ unfortunately with no resources to implement its recommendations. It argues that comprehensive treatment should be provided in four 'tiers'. Brief interventions are helpful at tiers one and two, that is in the community and in primary care respectively. But they must be backed up by specialist treatment, both in the community and in residential care (tiers three and four). Without specialist back-up, lower-tier interventions do not occur, or occur only sporadically. There is little point in identifying people with alcohol problems if there is nowhere to refer them. Brief interventions have little effect in alcohol dependence.

Specialist community alcohol teams are not very expensive, probably costing less per health district than the total cost of putting a child in care, or the legal and police costs associated with one fatal car crash, and nationally a fraction of the $\mathfrak{E} 8$ billion per year received from taxation on alcohol. Such services are hugely cost-effective by saving money and reducing social and physical harm caused by alcohol dependence. ${ }^{29}$ That they are not universally available is not only a scandal with regard to patient care, but also an example of irrational commissioning and policy development. It must not be allowed to continue.

Thomas Carnwath

\section{For: rebuttal and conclusion}

Dr Carnwath is correct in stating the damage that alcohol misuse causes and in pointing out that I have been selective in my reporting of the literature - I have chosen the largest, most powerful randomised trials available. Another trial has now been reported: the COMBINE study, a randomised controlled trial of eight alcohol interventions over 1 year with 1383 participants. ${ }^{33}$ Treatment involved combinations of 16-weeks naltrexone and acamprosate treatment and a 'combined behavioural intervention' based on cognitive-behavioural therapy. The placebo medication group reported $74 \%$ abstinent days over the period of study compared with $80 \%$ abstinent days in the best outcome group (naltrexone without additional psychotherapy). All groups received nine sessions of counselling. There was no benefit from additional specialised psychotherapy. Moreover, patients receiving placebo alone faired better than those receiving specialist psychotherapy without any form of medication ( $74 \% v .67 \%$ abstinent days respectively). Although the authors were predictably upbeat about the statistical differences, the study fails to demonstrate any clinically significant data considering the small size of the response (a maximum of a $7 \%$ reduction in the number of non-abstinent days). Although brief interventions are regarded as moderately effective in opportunistic samples, there remains no convincing evidence of the effectiveness of specialised treatment for treatment-seeking people with serious alcohol problems even in large, independent trials with highly motivated and compliant participants.

Jason Luty

\section{Against: rebuttal and conclusion}

Dr Luty is correct in pointing out that the difference between interventions for alcohol dependence is often small, even when one of the interventions is placebo. What he fails to point out is that most trials show very significant improvements in all conditions of treatment, and that placebo in alcohol research is often in itself a very meaningful intervention. For example in the COMBINE trial Dr Luty describes, the average improvement in all arms of the research was from less than 25\% abstinent days at initiation to over $70 \%$ at 16 weeks and over $60 \%$ after 1 year of the treatment. ${ }^{33}$ The 'standard medical management' in this trial consisted of as many as nine structured sessions initially of $45 \mathrm{~min}$, then of $20 \mathrm{~min}$, and research assessments alone consisted of up to $12 \mathrm{~h}$ of intensive questioning, a procedure which in itself can have a significant motivational effect. These were then compared with cognitive-behavioural therapy and other specialist interventions, and perhaps not surprisingly often performed just as well. In comparison with these standard or placebo interventions, one of the actual treatment interventions in the UKATT trial described by Dr Luty consisted of just $4 \mathrm{~h}$ of 'motivational interviewing. ${ }^{11}$ Dr Luty seems also to have misread the results in the UKATT trial when he stated that participants were still consuming on average 137 units of alcohol per week at the end of the trial. He appears to have interpreted the variable 'average drinks per drinking day' as 'average drinks per day', clearly a much higher figure than that actually found, since a marked increase in abstinent days 
was also observed. In fact the average annual intake was 72 units per week after the specialist intervention - certainly more than ideal, but much less than the initial intake of 132 units, and with a demonstrated economic benefit of between $\mathfrak{E} 700$ and $£ 1000$ per patient per year.

We can probably agree that brief and slightly longer interventions often produce very positive results in terms of health and economic benefit, even when these masquerade as placebo. In spite of this remarkable finding, even limited interventions are still not widely available in this country. This is perverse. We can also agree that treatment is only one factor in any improvement achieved, with independent social and personal factors being at least as important. One estimate is that 'treatment probably accounts for around one third of all improvements made. ${ }^{34}$ But when considering a problem as widespread as alcohol misuse, even a third is a large amount both in human and economic terms. Where people do not respond to self-help or to brief interventions alone, longer and more intensive involvement is justified. This is demonstrated by the many independent reviews of the evidence from several hundred trials, as I described above. To challenge this widespread consensus is brave, but to do so Dr Luty needs to do more than point to features of selected individual trials; he needs to challenge the methodology on which these reviews are based.

Thomas Carnwath

For: Jason Luty, MB, ChB, BSC, PhD, MIBiol, CBiol, MRCPsych, Consultant in Addictions Psychiatry, South Essex Partnership NHS Trust, Honorary Consultant in Addictions Psychiatry, Cambridge and Peterborough Mental Health Partnership NHS Trust, The Taylor Centre, Queensway House, Essex Street, Southend on Sea, Essex SS1 5QT, UK. Email: sl006h3607@blueyonder.co.uk

Against: Thomas Carnwath, Consultant Psychiatrist, Tees Esk and Wear Valleys NHS Trust, Kirkstone Villa, Earls House, Lanchester Road, Durham DH1 5RD, UK. Email Thomas.Carnwath@cddps.nhs.uk

\section{References}

1 Day L. NHS faces job cuts as financial crisis deepens. BMJ 2006; 332: 743.

2 Department of Health. A First Class Service - Quality in the New NHS. TSO (The Stationery Office), 1998.

3 Prime Minister's Strategy Unit. Alcohol Harm Reduction Strategy for England. Prime Minister's Strategy Unit, 2004 (http://www.cabinetoffice.gov.uk/upload/ assets/www.cabinetoffice.gov.uk/strategy/caboffce\%20alcoholhar.pdf).

4 Department of Health. Alcohol Needs Assessment Research Project (ANARP). TSO (The Stationery Office), 2005

5 Alcohol Concern. Report on the Mapping of Alcohol Services in England. Alcohol Concern, 2002 (http://www.nwph.net/alcohol/anarp.aspx).

6 Rehm J, Room R, van den Brink W, Jacobi F. Alcohol use disorders in EU countries and Norway: an overview of the epidemiology. Eur Neuropsychopharmacol 2005; 15: 377-88.

7 Crisp AH, Gelder M, Goddard E, Meltzer H. Stigmatisation of people with mental illness: a follow-up study within the Changing Minds campaign of the Royal College of Psychiatrists. World Psychiatry 2005; 4: 106-113.

8 Luty J. What works in alcohol use disorders. Adv Psychiatr Treat 2006; 12: 13-22.

9 Moyer A, Finney JW, Swearingen CE, Vergun P. Brief interventions for alcoho problems. Addiction 2002; 97: 279-92.

10 Project MATCH Research Group. Matching alcoholism treatments to client heterogeneity: project MATCH three-year drinking outcomes. Alcohol Clin Exp Res 1998; 22: 1300-11.

11 UKATT Research Team. Effectiveness of treatment for alcohol problems: findings of the randomised UK alcohol treatment trial (UKATT). BMJ 2005; 331: 541 .
12 Hughes JC, Cook $\mathrm{CCH}$. The efficacy of disulfiram: a review of outcome studies. Addiction 1997; 92: 381-95.

13 Chick J, Howlett $H$, Morgan MY, Ritson B, for UKMAS Investigation. The United Kingdom Multicentre Acamprosate Study: a 6-month prospective study of acamprostate versus placebo in preventing relapse after withdrawal from alcohol. Alcohol Alcohol 2000, 35: 176-87.

14 Krystal JH, Joyce JA, Krol WF, Kirk GF, Rosenheck RA. Naltrexone in the treatment of alcohol dependence. N Engl J Med 2001; 345: 1734-9.

15 Kiefer F, Jahn H, Taraske T, Helwig H, Briken P, Holzbach R, Kämpf P, Stracke $\mathrm{R}$, Baehr $\mathrm{M}$, Naber $\mathrm{D}$, Wiedemann $\mathrm{K}$. Comparing and combining naltrexone and acamprosate in relapse prevention of alcoholism: a double-blind, placebo-controlled study. Arch Gen Psychiatry 2003; 60: 92-9.

16 Lloyd JJ, Chen CY, Storr CL, Anthony JC. Clinical features associated with receipt of alcohol treatment. J Stud Alcohol 2004; 65: 750-7.

17 Vaillant GE. The Natural History of Alcoholism. Harvard University Press, 1983.

18 Edwards G, Orford J, Egert S, Guthrie S, Hawker A, Hensman C, Mitcheson M, Oppenheimer E, Taylor C. Alcoholism: a controlled trial of 'treatment' and 'advice.' J Stud Alcohol 1977; 38: 1004-31.

19 Wessely S / Deahl M. Psychological debriefing is a waste of time (in debate). Br J Psychiatry 2003; 183: 12-14.

20 Wright S, Gournay K, Glorney E, Thornicroft G. Dual diagnosis in the suburbs: prevalence, needs and in-patient service use. Soc Psychiatry Psychiatr Epidemiol 2000; 35: 297-304.

21 Department of Health. Alcohol Needs Assessment Research Project (ANARP): The 2004 National Alcohol Needs Assessment for England. Department of Health, 2004.

22 Miller WR, Wilbourne PD, Hetema JE. What works? A summary of alcohol treatment outcome research. In Handbook of Alcoholism Treatment Approaches: Effective Alternatives (3rd edn) (eds RK Hester, WR Miller): 13-63. Allyn and Bacon, 2003.

23 Berglund $\mathrm{M}$, Thelander $\mathrm{S}$, Jonsson $\mathrm{E}$ (eds). Treating Alcohol and Drug Abuse: An Evidence-based Review. Wiley-VCH, 2003.

24 Slattery J, Chick J, Cochrane M, Craig J, Godfrey C, Kohli H, Macpherson K, Parrott S, Quinn S, Single A, Tochel C, Watson H. Prevention of Relapse in Alcohol Dependence. Health Technology Assessment Report 3. Health Technology Board for Scotland, 2003.

25 Shand F, Gates J, Fawcett J, Mattick R. The Treatment of Alcohol Problems: A Review of the Evidence. Commonwealth Department of Health and Ageing, 2003.

26 Raistrick D, Heather N, Godfrey C. Review of the Effectiveness of Treatment for Alcohol Problems. National Treatment Agency, 2006.

27 Kenna GA. Pharmacotherapy of alcohol dependence: targeting a complex disorder. Drug Discov Today Ther Strateg 2005; 2: 71-8.

28 Project MATCH Research Group. Matching alcoholism treatments to client heterogeneity: Project MATCH post-treatment drinking outcomes. I Stud Alcohol 1997; 58: 7-29.

29 UKATT Research Team. Cost-effectiveness of treatment for alcohol problems: findings of the randomised UK Alcohol Treatment Trial (UKATT). BMJ 2005; 331: $544-7$

30 Glass IB. Undergraduate training in substance abuse in the United Kingdom. Br J Addict 1989; 84: 197-202.

31 Bertholet N, Daeppen J-B, Wietlisbach V, Fleming M, Burnand B. Brief alcohol intervention in primary care: systematic review and meta-analysis. Arch Intern Med 2005; 165, 986-95.

32 Department of Health. Models of Care for Alcohol Misusers. TSO (The Stationery Office), 2006.

33 Anton RF, O'Malley SS, Ciraulo DA, Cisler RA, couper D, Donovan DM, Gastfriend DR, Hosking JD, Johnson BA, LoCastro JS, Longabaugh R, Mason BJ, Mattson ME, Miller WR, Pettinati HM, Randall CL, Swift R, Weiss RD, Williams LD, Zweben A, for COMBINE Study Research Group. Combined pharmacotherapies and behavioural interventions for alcohol dependence: the COMBINE study. A randomised controlled trial. JAMA 2006; 295 2003-17.

34 Raistrick D, Heather N, Godfrey C. Review of the Effectiveness of Treatment for Alcohol Problems: 174. National Treatment Agency, 2006. 